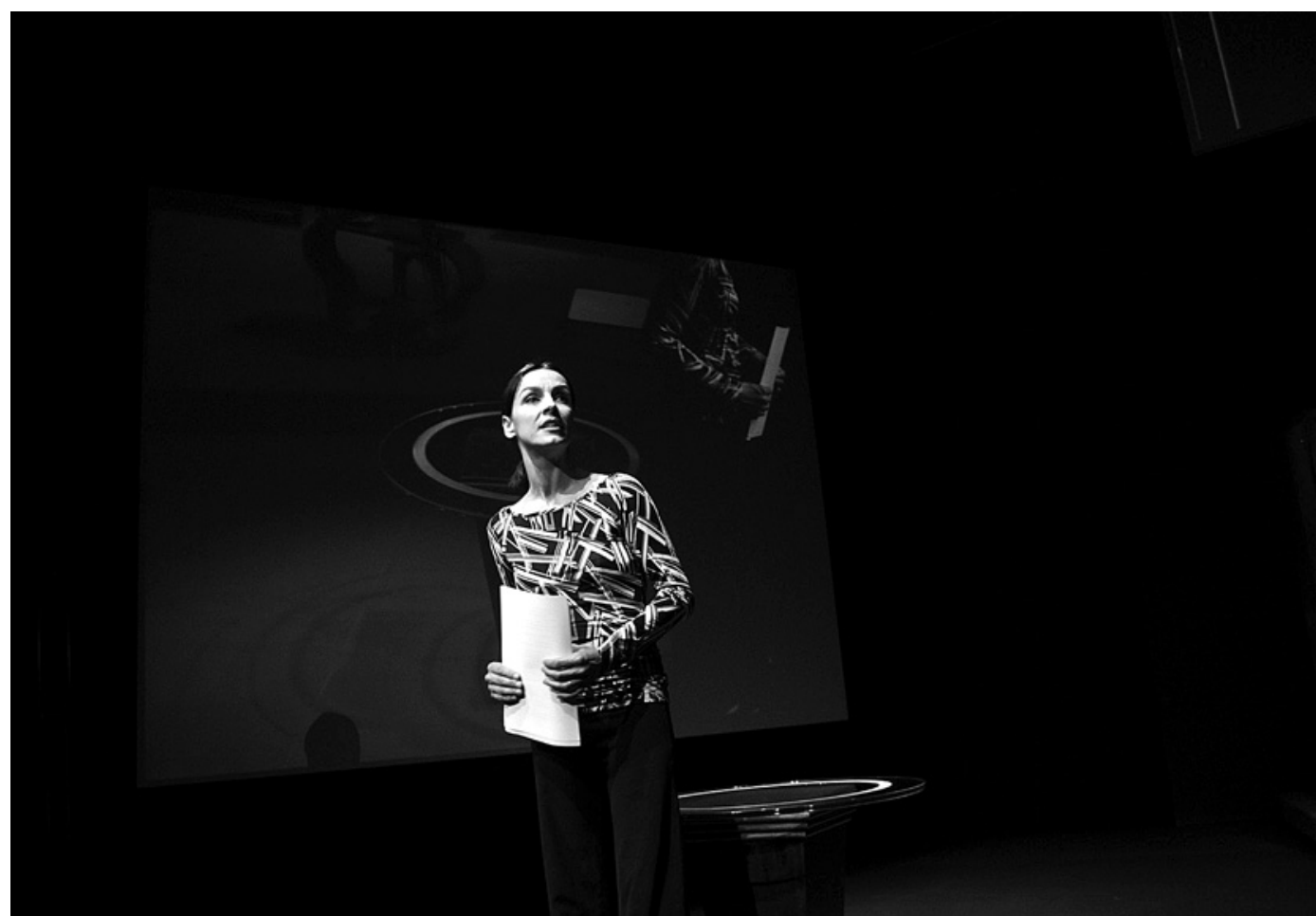

\title{
Meia dúzia de palavras e a tua vida...
} Stat Miller

Titulo: Londres (2011). Texto: Cláudia Clemente. Encenação, realização de vídeo e luz: João Lourenço. Dramaturgia: Vera San Payo de Lemos. Cenário: António Casimiro e João Lourenço. Figurinos: Graça Rodrigues. Supervisão audiovisual: Nuno Neves. Interpretação: Carla Maciel. Produção: Novo Grupo / Teatro Aberto. Local e data de estreia: Teatro Aberto, Lisboa, 30 de Setembro de 2012.

Quando pensamos na cidade de Londres, muitas vezes, a primeira coisa que nos vem à cabeça são as férias, os passeios, os monumentos, os museus, os momentos passados em família ou com amigos numa das capitais europeias mais frequentadas por turistas. Londres é, metonimicamente, a Londres da Tate Modern, do Big Ben, do chá das 5, da Rainha e do palácio de Buckingham, do Museu de História Natural, da Abadia de Westminster e de tantos outros locais turísticos. Londres, a peça de Cláudia Clemente, joga, no titulo, com essas expectativas. Mas a Londres que encontramos em Londres não é a cidade que conhecemos dos roteiros turísticos. Esta Londres, desta autora e desteespectáculo é uma cidade diferente, a viagem é outra e as paragens também. Londres é um espectáculo do luto.

0 texto de Cláudia Clemente, com encenação de João Lourenço, é um poema para a cena: um monodrama que vive da cumplicidade possivel entre factos verídicos e teatralidade. A actriz Carla Maciel gere, em cena, todo o dispositivo cénico e técnico (projecções vídeo e registos áudio) que traduzem esta viagem particular à capital inglesa. Assim, Ela, a personagem a que Carla Maciel dá corpo e que é uma clara - e declarada - projecção da autora do texto, é uma filha que acompanha os pais a Londres, cidade onde estudou, na esperança de encontrarem ali o tratamento adequado para a doença do pai. 0 discurso da actriz mantém o registo confessional e intimista do texto: olha-nos nos olhos e conta-nos todos os pormenores dessa viagem absolutamente exclusiva e pessoal da autora. Encontra-se uma duplicidade do trabalho da actriz, que é simultaneamente ela própria e a voz autoral da viagem relatada: Carla Maciel está em cena em representação da autora do texto, toma de empréstimo as suas palavras, as suas emoções e os seus sentimentos, materializando-os e tornando visível a viagem.

É a actriz que gere todo o dispositivo cénico, activando os ambientes sonoros e as imagens que melhor servem as potencialidades técnicas para a sua confissão. As imagens projectadas acompanham todo o desenrolar da narrativa, variando entre a transmissão de planos subjectivos e a manipulação da imagem em cena. As imagens

("verdadeiras") que vemos de Londres, familiares, que reconhecemos das nossas histórias pessoais, das memórias felizes de quem é turista nesta cidade, neste espectáculo surgem em contraponto com a narrativa clínica e patológica que nos está a ser contada. Todo o espectáculo é pontuado pelos títulos projectados que definem estações, zonas espaciais (No hospital, No hotel, Pelas ruas de Londres, A abadia) e emocionais ( $A$ doença, Os contos, $O$ chá, As radiografias, $A$ actriz, Oitenta e cinco), que vão situando a acção narrativa e a descrição da viagem. A associação da forma multimédia de escrita cénica com o registo intimista
Stat Miller

é Mestre em Encenação e licenciada em Dramaturgia pela Escola Superior de Teatro e Cinema. 

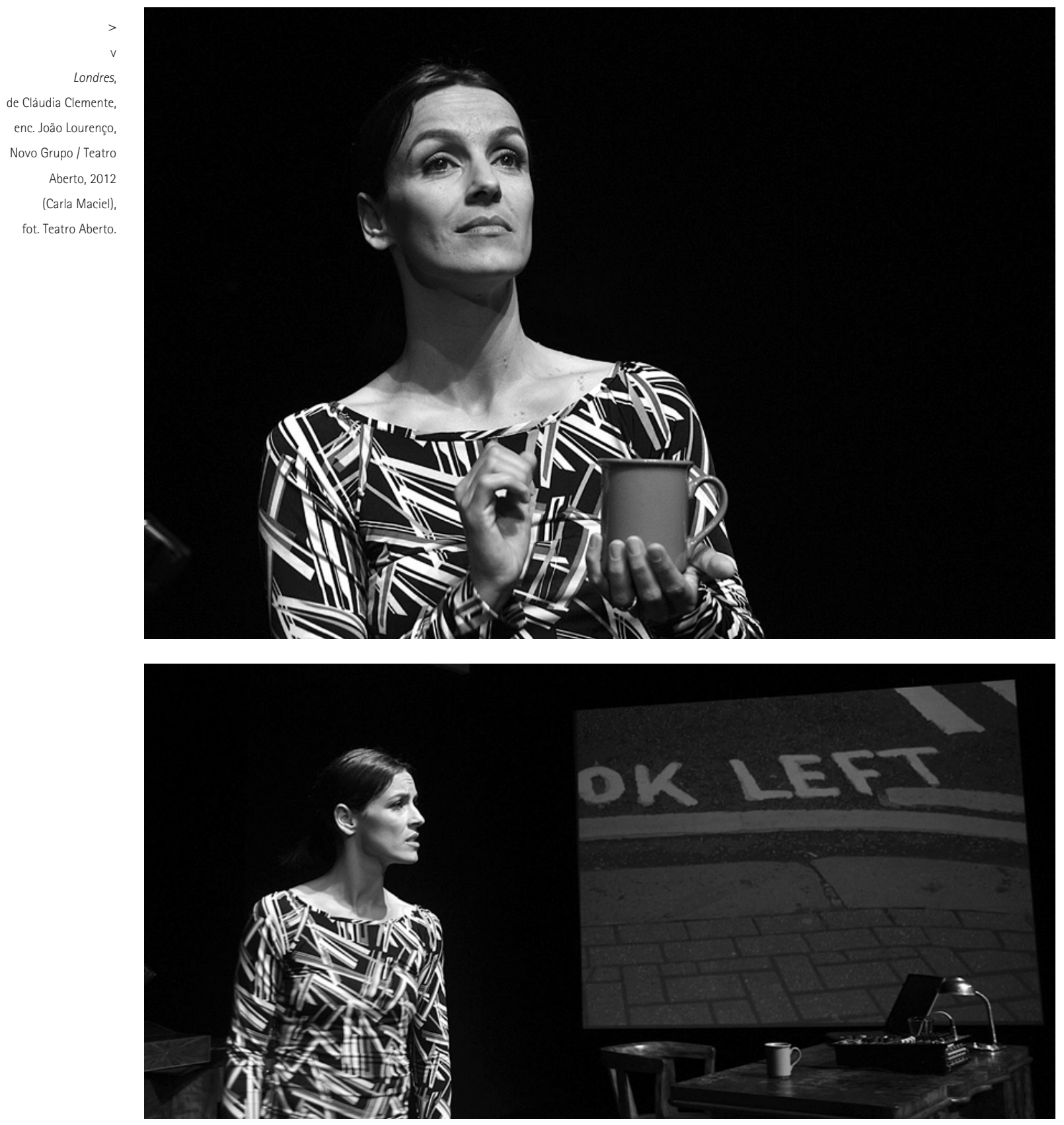

da actriz (e do próprio espectáculo) funciona melhor quando as imagens projectadas nos três telões do cenário mostram planos subjectivos do percurso narrativo da personagem - quando, de algum modo, sugerem uma ilustração reveladora das memórias da personagem. 0 discurso é tão autêntico quanto as imagens projectadas nos telões, que concretizam o confronto entre o destino turístico e o passeio até à morte. A acção do texto é dilatada porque 0 exterior é trazido constantemente para o palco. $E_{\text {, }}$ efectivamente, é esse exterior - estranho, um corpo estrangeiro que conduz a actriz no seu percurso - que amplia as suas dificuldades e hiperboliza os seus sentimentos e emoções (que só por si, e mesmo que o contexto fosse mais "nacional", seriam difíceis de minimizar). 0 cenário é uma espécie de sinédoque que serve de sugestão de todos os ambientes em que a história se desenrola, porque é de ambientes, de zonas de espaços físicos que esta história é feita. É mais ou menos claro que uma experiência traumática como esta que é trazida à cena é quase sempre indissociável dos espaços em que ela nos acontece, mais ainda quando se trata de um espaço estranho, não familiar estrangeiro. As palavras são diferentes, os hábitos alteramse, e mesmo o habitual chá nocturno da mãe se torna um problema (não se encontra em lado nenhum o que costuma beber), uma metáfora que aponta para toda a conjuntura adversa que ameaça o universo destas personagens.

É de enfatizar o virtuosismo da actriz que chama a si o controlo do espectáculo, no modo como produz o discurso narrativo e acciona o dispositivo técnico de cena que serve o texto, ampliando em palco a dimensão e a emotividade das palavras. 0 fim talvez propositadamente pouco denunciado faz com que a história fique em suspenso, talvez porque seja melhor não saber "quanto tempo de vida nos restará a cada um de nós" e "talvez seja melhor assim". "Uma palavrita de merda / Meia dúzia de palavras e a tua vida vem-se abaixo: Cancro". 